\title{
Hydraulic Analysis and Modelling of Water Distribution Network Using WATERCAD and GIS: AL-Karada Area
}

\author{
Noor R. Kadhim ${ }^{1, \text { a, }}$, Khalid A. Abdulrazzaq ${ }^{1, \text { b }}$, and Athraa H. Mohammed ${ }^{1, c}$ \\ ${ }^{1}$ Department of Civil Engineering, University of Baghdad, Baghdad, Iraq. \\ an.kathum1101@coeng.uobaghdad.edu.iq, baleoubaidy@coeng.uobaghdad.edu.iq, \\ cdr.athraa.h@coeng.uobaghdad.edu.iq
}

\begin{abstract}
The hydraulic study of drinking water is one of the things that must be done in order to obtain a realistic perception of the network's functioning and the problems it suffers from, As well as to reach the scientific method to expand it if required, knowing that the population density is constantly increasing, as is the urban expansion, The aim of this study is evaluated and analyzed alkarada water distribution network to determine the areas of pure water scarcity and its causes, and the study relied on the data of the Baghdad water supply administration for the year 2020 and its divisions, where a hydraulic model of the network was created for the purpose of analysis, it included a review of the pressures and speeds during the average daily demand per person of 350 liters / day and during the maximum operational design capacities of the compacts Units, the results showed that the pressures within the acceptable limits and the flow velocity are not excessive in some pipe due to the low average daily demand.
\end{abstract}

Keywords: Hydraulic analysis; drinking water; WATERCAD; simulation; GIS.

\section{Introduction}

Water utilities offer drinking water supply to local municipalities and tax the service through the metered water intake. However, not every drop of water generated hits consumers and produces income for municipalities. Instead, a large amount of drinking water is diverted, owing to either water dripping away from the delivery pipes or the illegal water use. Consequently, water utilities lose the revenue within distribution pipeline networks. Water loss represents a major fraction of non-revenue water [1]. The coming of age of the water infrastructure poses creates a growing obstacle for utility administrators. One of the main challenges is to measure the long-term development of network recovery demand. The motivation is to ensure that adequate money is collected and properly distributed to achieve the foreseen quality of operation. Consequently, the last decade of water infrastructure management has seen increased growth, testing, and implementation of mathematical models in rehabilitation planning and network failure estimation [2]. In common engineering practice, water treatment systems are constructed using only heuristic parameters. Determining the optimum design and network parameters that can satisfy necessary flow and pressure intensity are the product of hydraulic and cost-benefit studies. The risk of device failure and other stability figures are very seldom used in such studies [3].

A good water distribution network should meet the following requirements [4,5]: (i) Water quality should not deteriorate in the system; (ii) Every consumer should get sufficient water at desired pressure; (iii) The design and layout should be economical; (iv) The system should meet fire demand; (v) It must afford easy maintainability, and (vi) Deliver water of correct quality and quantity continuously with minimum service interruptions. Softwares like the LOOP, EPANET, and WaterCAD have been used for hydraulic simulation of the water distribution system though the latest software WaterCAD is the most advanced and powerful tool used in the present analysis [6]. This paper focuses on constructing a hydraulic network model and illustrating the hydraulic network analysis of Karrada. 


\section{Material and Methods}

Study Area Description. Al-Karada water supply is located near the zone of Al-Rasafa section on the eastern bank of the Tigris and has an area of $11.96 \mathrm{~km}^{2}$ and the population of 92400 per capita, [7], as shown in Figures 1, 2. Water supply network R9 is supplied from Sharik Dijla treatment plant by the main transmission pipeline and Al-Jadria and AL-Fateh AL-Mobin Compact Unit, as shown in Figure 3. R9 network supplied potable water to the districts $(901,903,905,907,909,911,913,915$, $919,921,923,925,929)$ in Al-Karada sector, the pipelines are designed for normal operating pressure up to 9.4 bars and are tested to 13.6 bars. Air Valves are provided at all high points along the pipeline, and down points are the washouts. These air valves will ensure that the transmission pipeline's minimum pressure should not be less than $3 \mathrm{~m}$ below the atmospheric pressure. Washout chambers are provided along the route to houses. The sluice valve is provided to facilities drainage of isolated pipeline section for maintenance and reparations. [8,9].

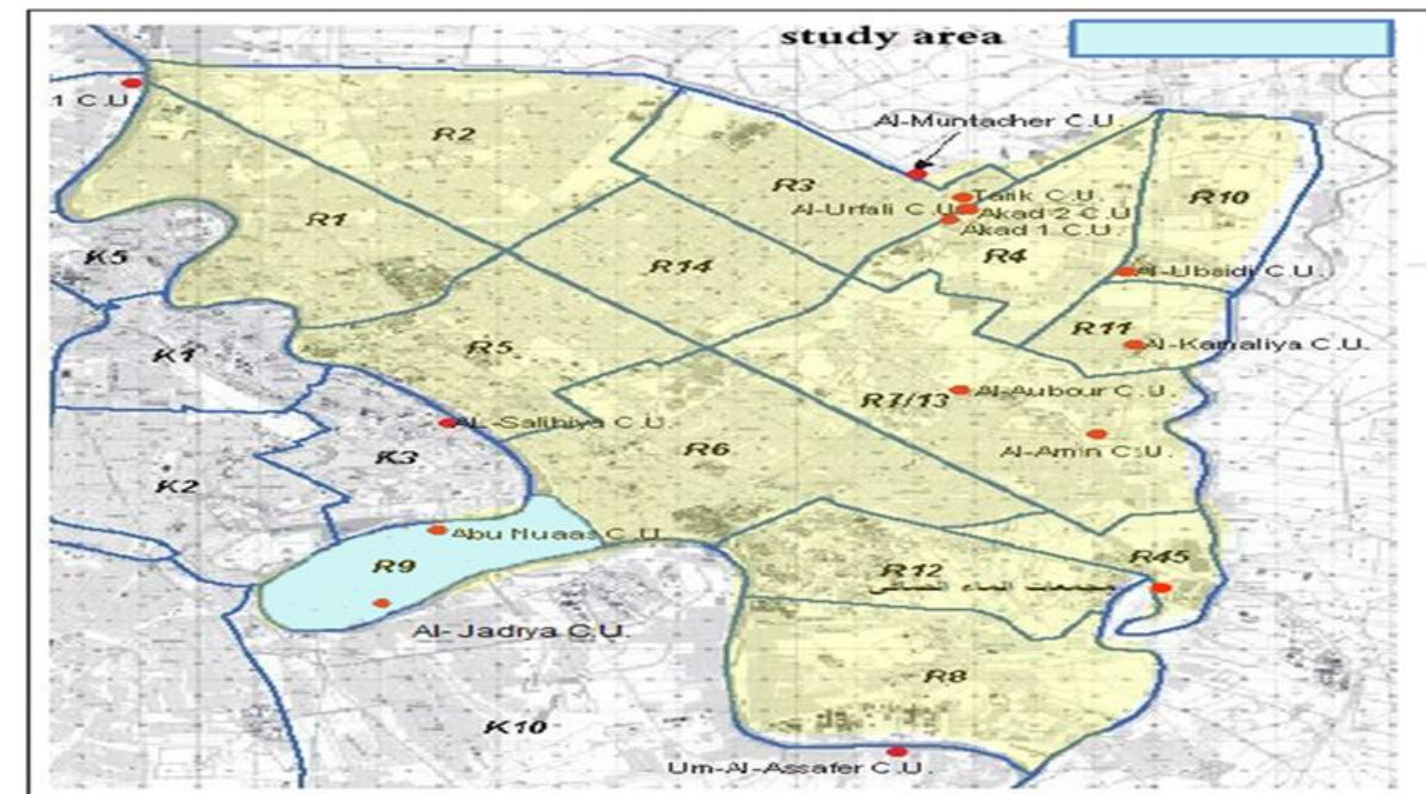

Figure 1. Sectors from Baghdad city represent Al-Karada water supply (R9 ZONE) [7].

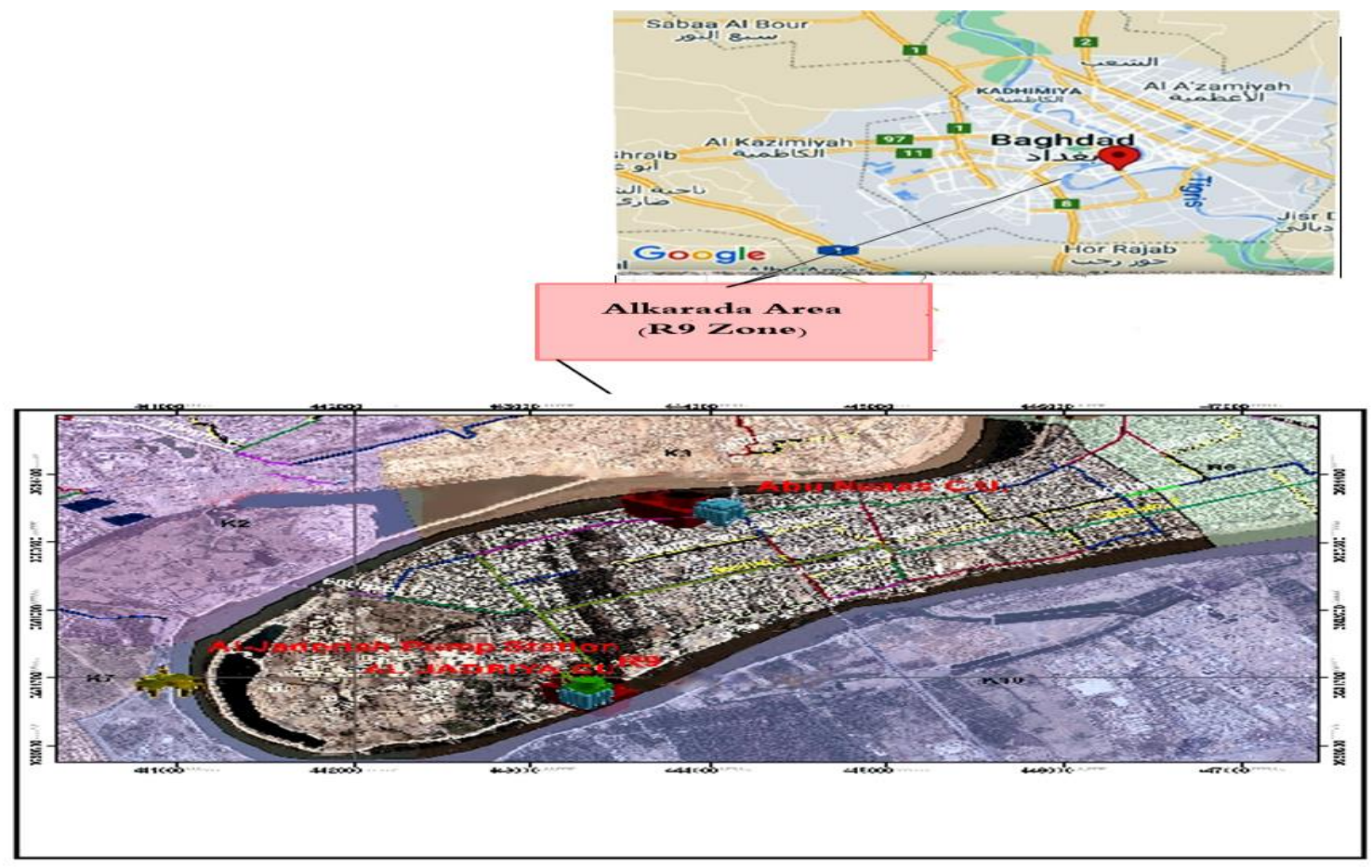

Figure 2. R9 Zone and location work by GIS. 


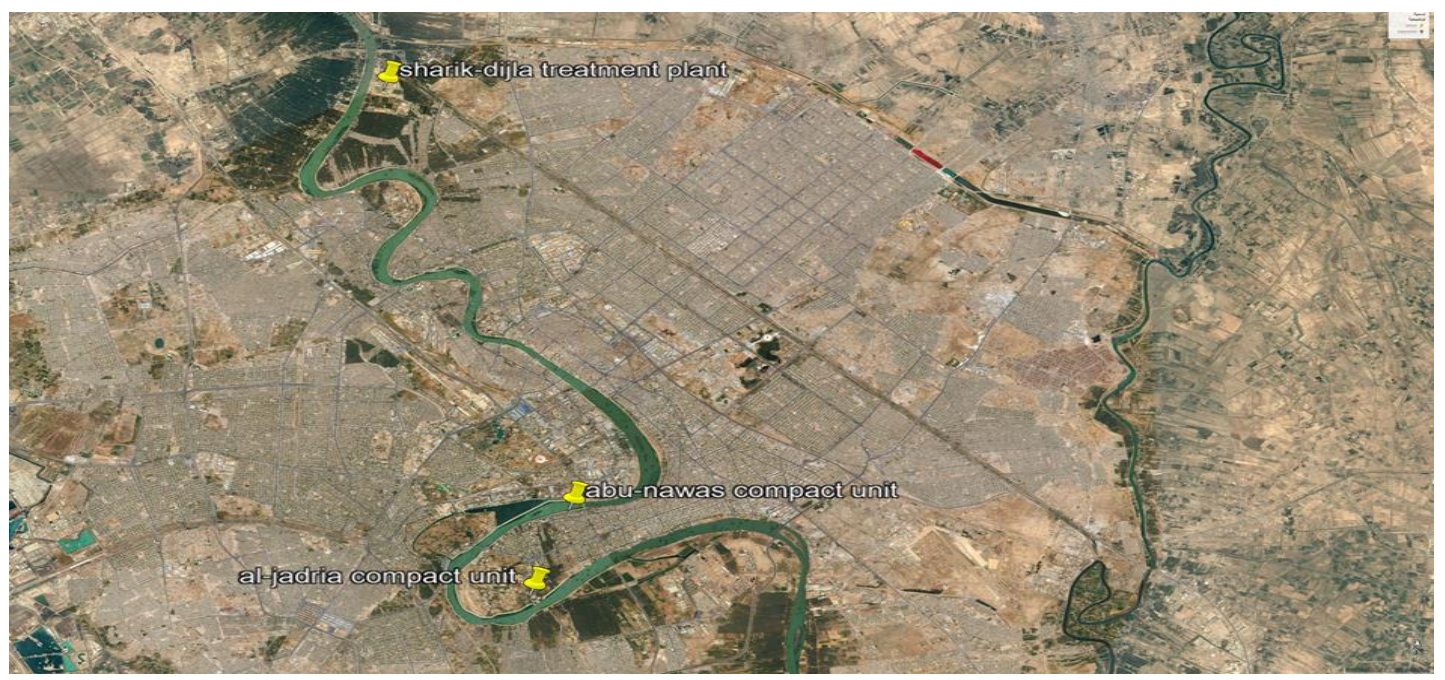

Figure 3. The project and compact units feeding R9 water network.

Data collection. The data and plans used in this research were obtained from the Baghdad Water Department or its affiliated sites from other departments not linked to the Municipality of Baghdad, such as the Ministry of Planning and the Ministry of Trade, to obtain data on population densities as well as historical data about the water network and the companies that installed these networks.

The Geographic Information System. GIS is taken as an aid to visualize the sources and feeders and conceptualize the entire distribution network. GIS integrates stores, edits, analyzes, shares, and displays geographic information for informing decision-makers [10]. The topographical elevations of the stand posts, houses, and other demand points are obtained from the GIS software. A geographical database was established for the main water pipeline network, and the water sources and reservoirs for the R9 network were identified as shown in Figure 4, and attribute table generation is performed for data preparation for Water GEMS software.

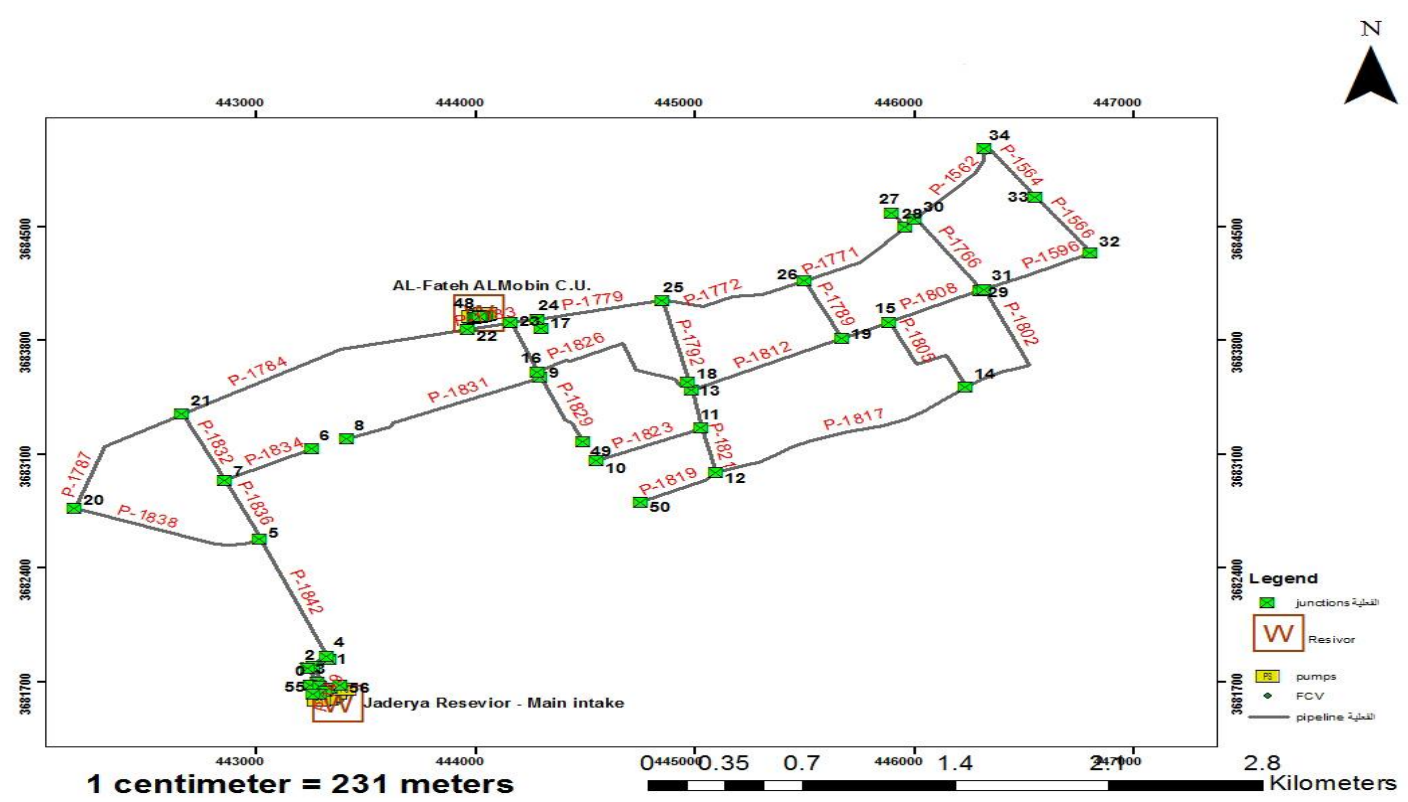

Figure 4. The main water pipeline of Al-Karada network.

Bentley Water GEMS. Is a multi-platform hydraulic and water quality modeling solution for water distribution systems with advanced interoperability, geospatial model-building, optimization, and asset management tools [11]. WaterCAD is an easy-to-use hydraulic and water quality simulation technology for water treatment systems. Utilities, towns, and engineering companies trust WaterCAD as a secure, resource-saving, decision-support application for their water infrastructure. WaterCAD 
lets engineers and utilities assess, plan, and optimize water delivery systems, from fire flow and constituent concentration analyses to energy cost control and pump simulation.

\section{Field Work and Method of Measurements}

The procedure of measurements was carried out by placing the bourdon gauge inside the washout chamber that gave the pressure. The measurements were done with the help of Baghdad water supply administration (BWSA). The measurements were performed in Winter 2021, during peak demand hours, as shown in Figure 5.

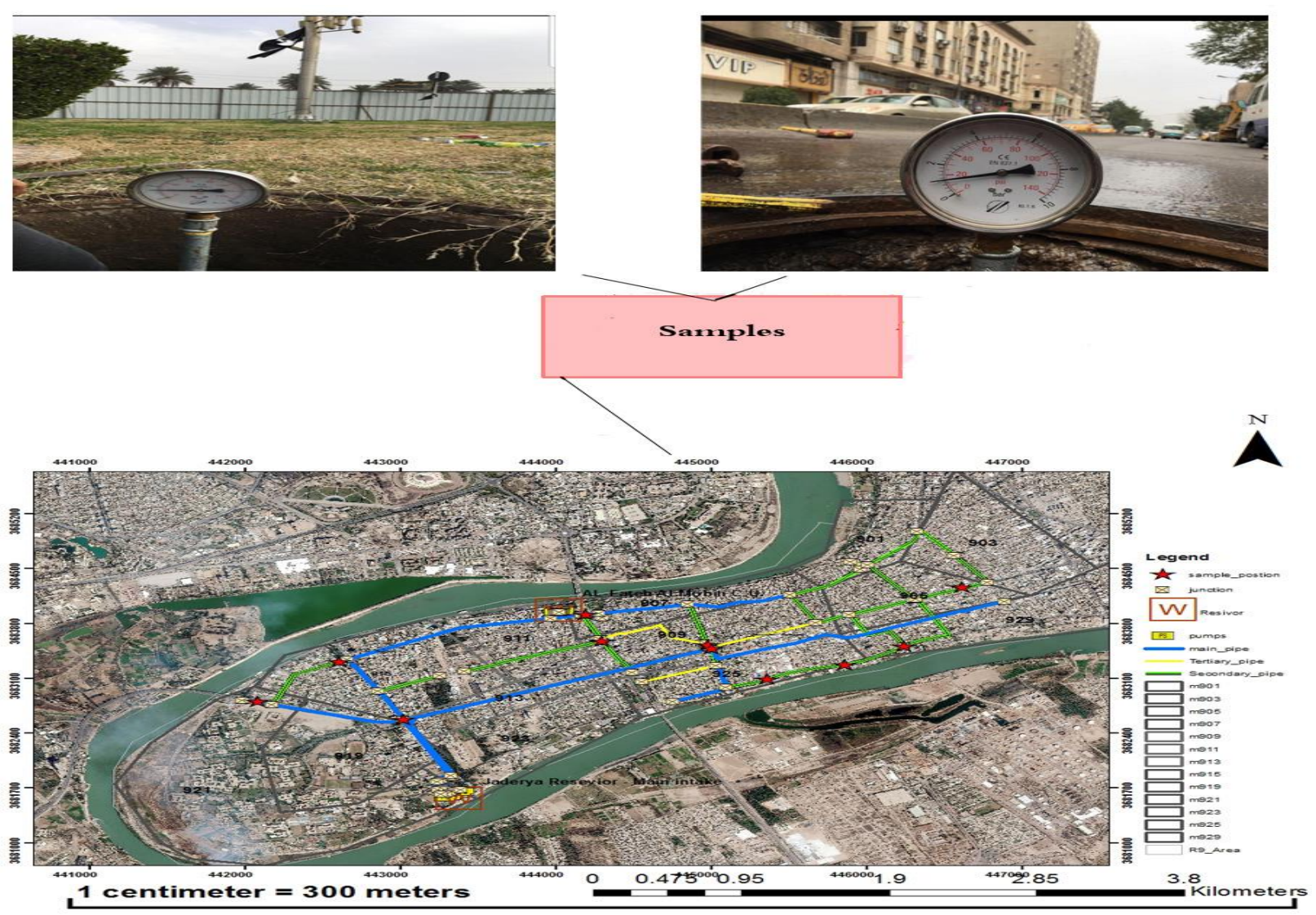

Figure 5. Field work measurements.

\section{Calculations}

The Hazen-Williams formula is the most commonly used head loss formula for the hydraulic head lost by water flowing in a pipe due to friction with the pipe walls. It is being used for the present study [12]. The Hazen- Williams equation is used for calculating the head loss in the network, and the main pipelines and the distribution pipelines are designed based on the required discharge and the velocity of flow using Manning's equation [13]. A continuous supply is assumed to maintain the necessary supply and pressure throughout the distribution system. For the present case, the attributes for the reservoir, tanks, pumps, junctions, and pipes have been entered using the Symbology Definitions tab. The pump head versus discharge curve with pump efficiency is entered in the Pump Definitions tab. The average daily consumption of 350 lpcd has been entered in the Scenario Manager tab. The steadystate solver options have been used in the analysis.

The efficiency of pumps is taken as $90 \%$ considering optimal operations [14]. The residual pressure to be maintained is $7 \mathrm{~m}$ for a sufficient flow in houses [15]. The information about network elements includes Pipes (length, roughness, diameter, and material); Pumps (number of pumps in the pumping station and pump curve or pumps characteristics); Valves (minor losses coefficient, material type of valve, type operation, diameter); Reservoir (number of compartments, volume and 
connections, shape, elevation) [16,17]. Distribution pipelines with a total length of $26.89 \mathrm{~km}$ all pipe materials are ductile iron. The pipeline of R9 network is generally between (1200mm to $200 \mathrm{~mm}$ ), composed of pipes with Hazen Williams pipe carrying capacity factor $\mathrm{C}=120$.

\section{Results and Discussion}

Hydraulic Analysis of Network. The network was analyzed using the Water GEMS program on the basis of two scenarios, through which they were compared, and the optimal scenario was found on the basis of the proposals, and conclusions were approved as follows:

- The first scenario (I): Considering that the compacts units are operating at full design capacity in terms of pressure and flow, and the program analyzed the network, and it was found through the analysis that the areas of scarcity are few and confined to the edges of the area where the pressures range from (0.71-2.2) bar and the velocity was $(0.04-1.91) \mathrm{m} / \mathrm{s}$ as shown in Figure 7.

- The second scenario (II): Considering that the compacts units are operating at total actual capacity in terms of pressure and flow. The program analyzed the network, and it was found through the analysis that the state of scarcity increased in the area, where the pressures ranged from (1.85-0.28) bar, and the speed was (1.91-0.04) $\mathrm{m} / \mathrm{s}$ as shown in Figure 8.

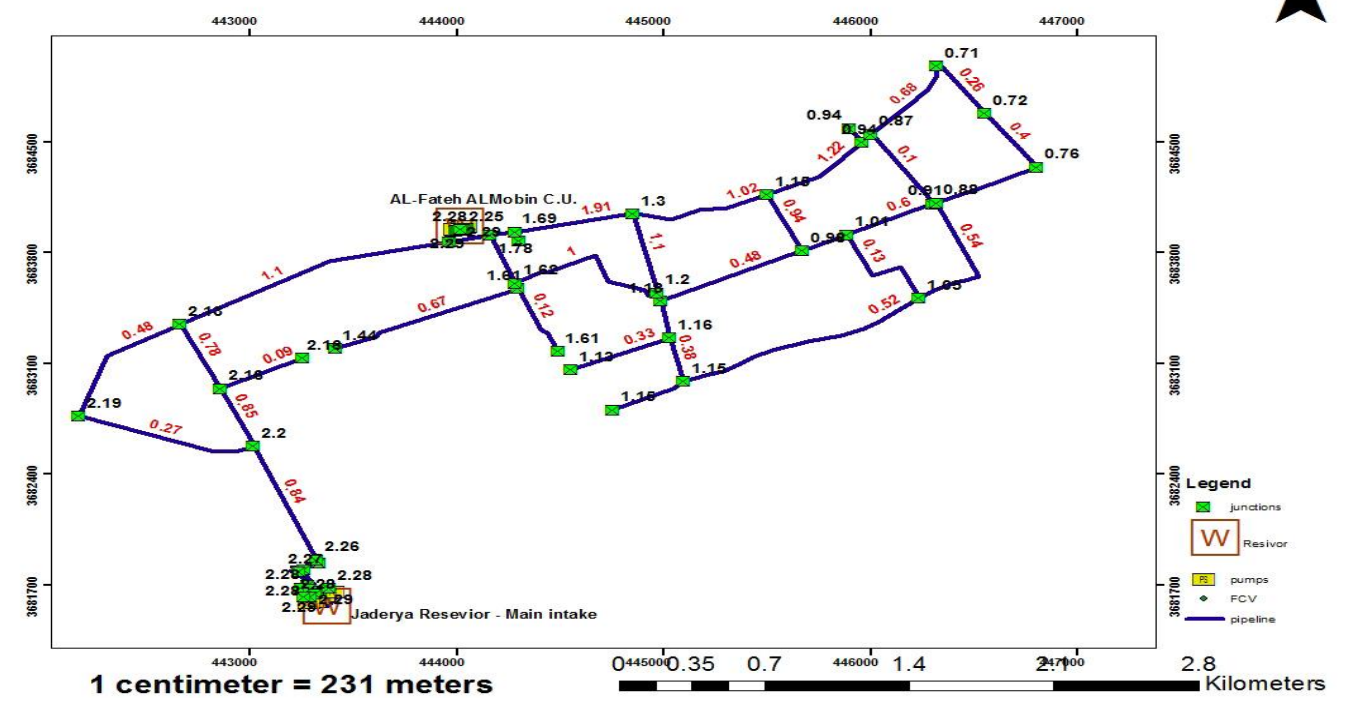

Figure 7. Scenario (1) work by GIS.

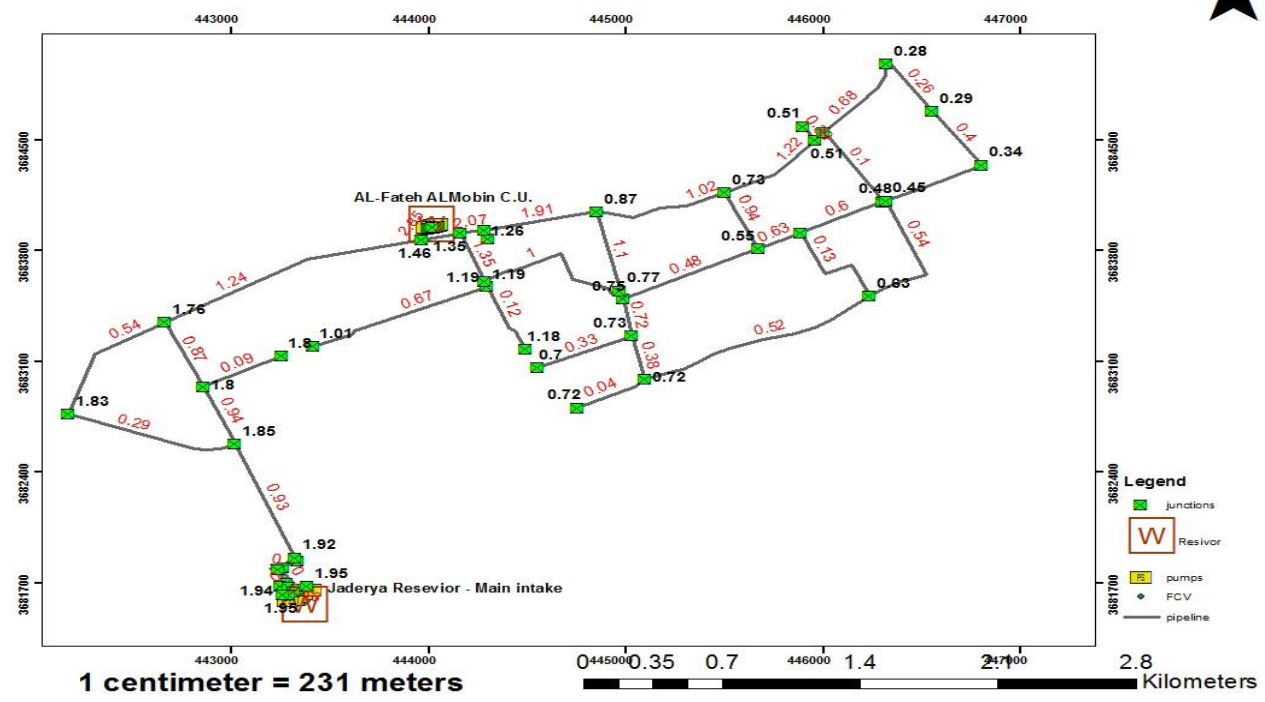

Figure 8. Scenario (2) work by GIS. 
Comparison of Hydraulic Analysis Result with Field Measurement. Through field visits to the study area and matching the reality of the situation with what has been obtained, as shown in table 1, it was observed that there is a difference between the case of the analysis and the situation in the area, and the reasons for these differences are:

- The use of domestic water pumps by all citizens leads to a decrease in water pressure whenever the area is further from the water source, and therefore the water does not reach the last point as planned. Where we notice through the results that the pressure ranges between $(0.71-2.2)$ bar, which is a good value as the standard value (150-200) $\mathrm{kPa}$ equivalent (1.4-1.9) bar for normal use in areas where residential buildings do not exceed 4 floors and are not equipped with extinguishing units [18].

- The presence of depressions and cracks in the pipes due to the virtual aging of the pipes, which leads to the interruption of water pumping.

Table 1. The Comparison of hydraulic analysis result with field measurement.

\begin{tabular}{|c|c|c|c|c|}
\hline $\begin{array}{l}\text { Node } \\
\text { No. }\end{array}$ & LABEL & $\begin{array}{l}\text { Pressure calculated (II) } \\
\text { (bar) }\end{array}$ & $\begin{array}{c}\text { Pressure field } \\
\text { Measurement (bar) }\end{array}$ & Error (\%) \\
\hline 5 & $\mathrm{~J}-642$ & 1.85 & 1.7 & 0.08 \\
\hline 6 & $\mathrm{~J}-641$ & 1.80 & 1.6 & 0.11 \\
\hline 7 & $\mathrm{~J}-640$ & 1.80 & 1.6 & 0.11 \\
\hline 8 & $\mathrm{~J}-639$ & 1.01 & 0.9 & 0.10 \\
\hline 9 & J-638 & 1.19 & 1 & 0.15 \\
\hline 10 & $\mathrm{~J}-637$ & 0.70 & 0.6 & 0.14 \\
\hline 11 & J-636 & 0.73 & 0.55 & 0.24 \\
\hline 12 & $\mathrm{~J}-635$ & 0.72 & 0.71 & 0.01 \\
\hline 13 & J-633 & 0.75 & 0.7 & 0.06 \\
\hline 14 & $\mathrm{~J}-632$ & 0.63 & 0.6 & 0.04 \\
\hline 15 & J-631 & 0.58 & 0.5 & 0.13 \\
\hline 16 & $\mathrm{~J}-630$ & 1.19 & 0.7 & 0.41 \\
\hline 17 & J-629 & 1.26 & 1.1 & 0.12 \\
\hline 18 & $\mathrm{~J}-628$ & 0.77 & 0.76 & 0.01 \\
\hline 19 & $\mathrm{~J}-627$ & 0.55 & 0.4 & 0.27 \\
\hline 20 & J-626 & 1.83 & 1.6 & 0.12 \\
\hline 21 & J-625 & 1.76 & 1.6 & 0.09 \\
\hline 22 & J-624 & 1.46 & 1.4 & 0.04 \\
\hline 23 & $\mathrm{~J}-623$ & 1.35 & 1.2 & 0.11 \\
\hline 24 & J-622 & 1.26 & 1 & 0.20 \\
\hline 25 & J-621 & 0.87 & 0.7 & 0.19 \\
\hline 26 & J-620 & 0.73 & 0.6 & 0.17 \\
\hline 27 & J-619 & 0.51 & 0.4 & 0.21 \\
\hline 28 & J-618 & 0.51 & 0.4 & 0.21 \\
\hline 29 & J-617 & 0.48 & 0.3 & 0.37 \\
\hline 30 & J-616 & 0.45 & 0.3 & 0.33 \\
\hline 31 & J-562 & 0.45 & 0.3 & 0.33 \\
\hline 34 & $\mathrm{~J}-550$ & 0.28 & 0.2 & 0.28 \\
\hline 35 & R9 Trunk & 1.94 & 1.8 & 0.07 \\
\hline 47 & $\mathrm{~J}-1104$ & 1.71 & 1.6 & 0.06 \\
\hline 48 & $\mathrm{~J}-1105$ & 1.69 & 1.5 & 0.11 \\
\hline 50 & J-1169 & 0.72 & 0.6 & 0.16 \\
\hline 55 & $\mathrm{~J}-48$ & 1.95 & 1.7 & 0.12 \\
\hline 56 & $\mathrm{~J}-50$ & 1.95 & 1.7 & 0.12 \\
\hline
\end{tabular}




\section{Conclusions}

In this study, hydraulic analysis and modeling of the AL-Karada water network, and from the results of the hydraulic analysis of the network, it was found that:

- AL-Karada, water supply network, will be within the optimal operation scheme if the compacts units work with the total design capacity.

- The effect of Hazen Williams coefficient (c) and the age of pipes on the hydraulic analysis of network where the pressure will increase with c value up to 130.

- The effect of operation the R9 Reservoir in the Karrada network led to an improvement in the current network pressures' performance, where the minimum pressure was $(0.71 \mathrm{bar})$, and the maximum pressure was (2.2 bar).

- As for the most important recommendations that we reached, they were as follows:

- To improve the field measurements, it recommended putting a pressure gauge in the draw-off nodes to represent the actual pressure head simultaneously for different nodes. Also, flow meters are to be provided at the nodes to estimate the total demand variation during the study period.

- Periodical field measurement for the head and flow rates to study the effect of Hazen Williams coefficient in the network.

\section{Acknowledgment}

The authors would like to thank the staff of the Department of design and execution in Baghdad water supply administration (BWSA), Especially engineer Saad Hilal (Head of execution department/Baghdad water supply administration), for their help in providing all information, maps, field work required in completing this work.

\section{References}

[1] Wu, Z.Y., 2008. Innovative optimization model for water distribution leakage detection. Watertown, USA: Bentley Systems Inc.

[2] Scholten, L., Scheidegger, A., Reichert, P. and Maurer, M., 2013. Combining expert knowledge and local data for improved service life modeling of water supply networks. Environmental Modelling \& Software, 42, pp.1-16.

[3] Dasic, T. and Djordjevic, B., 2004. Method for water distribution systems reliability evaluation.

[4] Heavens, J.W. and Gumbel, J.E., 2002. To Dig or not to Dig: Design, Specification and Selection Issues in the Trench less Renovation of Water mains. Assessing the future of water utility Infrastructure Management. DM Hughes (Ed.) AWWA, Denver, Co. USA.

[5] Garg, S.K., 1977. Water supply engineering.

[6] azari, A. and Meisami, H., 2008. Instructing WaterGEMS software usage. Water Online: Exton, PA, USA.

[7] Japan International Cooperation Agency, 2006, The feasibility study on Baghdad water supply system improvement project, Final Report, Volume I, Executive Summary, Unpublished data.

[8] Alshammery, H., 2004. Water pressure equalization in pipe. M.Sc. Thesis, University of Baghdad, Iraq.

[9] Hado, J. M. N., 2014. The hydraulic study of the water distribution network for the Rusafa area. Scientific and Technical Consultation Bureau, Ministry of Science and Technology, Iraq.

[10] Caliper.,2020.MaptitudeMappingSoftware. https://www.caliper.com/maptitude/gis_software/default.htm

[11] Ramesh, H., Santhosh, L. and Jagadeesh, C.J., 2012. Simulation of hydraulic parameters in water distribution network using EPANET and GIS. In International conference on ecological, environmental and biological sciences, Dubai, pp. 350-353. 
[12] Bentley Systems Incorporated, WaterCAD/GEMS V8i, 2012. Water distribution design and modeling, fundamentals. Version V8i (SELECT series 3) (metric), Bentley Institute Course Guide, USA.

[13] Mays, L.W., 2010. Water resources engineering. John Wiley \& Sons.

[14] Baghdad water supply administration ,2020, operating Department, Unpublished data.

[15] India. Ministry of Urban Development. Expert Committee, Central Public Health and Environmental Engineering Organisation (India), 1999. Manual on water supply and treatment. Central Public Health and Environmental Engineering Organization, Ministry of Urban Development, India.

[16]U. S. Environmental Protection Agency, 2005. Water Distribution System Analysis: Field Studies, Modeling and Management, A Reference Guide for Utilities Cincinnati, Ohio, USA.in water distribution systems", 30th WEDC International Conference, Vientiane, Lao PDR, 2004.

[17] Gavekari, V. and Nandavadekar, V. D., 2013. Integration of GIS based decision support system for operations and maintenance of water network. International Journal of Computer Science Engineering and Information Technology Research (IJCSEITR), 3(5), 185-194.

[18] Mawlood, IA.,2010. Hydraulic Analysis of Fallujah Water Network by Using a Program EPANET, Anbar Journal of Engineering Sciences,3(2),112-124. 